\title{
A trajetória da pesquisa na Sociologia
}

MARIA ARMINDA DO NASCIMENTO ARRUDA

A s expressóes atuais da reflexão sociológica brasileira, os seus horizontes e orientaçōes mais significativas, vinculam-se, estreitamente, à construçáo do curso de Ciências Sociais, no âmbito da Faculdade de Filosofia da Universidade de São Paulo. E, de fato, a tarefa de mapear uma temática e erigir um estilo de reflexão, pautado por princípios da produção do conhecimento e ancorado em investigaçóes rigorosas, repousou, inicialmente, nas mãos dos mestres estrangeiros. $O$ desenvolvimento da sociologia associou-se à organizaçáo da Universidade, à medida em que esta iria lhe conferir imprescindível espaço institucional, ao manter a recorrência da formação, ao ser capaz, enfim, de ofertar condiçóes estáveis ao pleno exercício da disciplina, na sua vertente acadêmica. A partir desse momento, o cenário intelectual modula-se por solicitaçóes qualitativamente diferenciadas, submetido ao influxo das exigências do saber universitário, recortando novos espaços e assenhorando-se de procedimentos anteriormente praticados de modo assistemático. Em outros termos, a tradição do saber sociológico é vigilantemente preservada e principalmente transmitida, quase ì buis clos, apesar dos seus produtos ultrapassarem o leito institucional.

A penetraçáo que adquiriram os estudos sociológicos brotados na academia já indica a presença de marcante sensibilidade intelectual, voltada à compreensão dos fenômenos afeitos à sociedade. A produção dos considerados precursores, posteriormente dos denominados intérpretes do Brasil, está a indicar o adensamento paulatino que as abordagens sociológicas vinham conquistando. Por essa razăo, os fundadores da sociologia universitária não se deparam com um ambiente cultural em inicialidade absoluta, no que tange à reflexáo específica. A grandé transformação originou-se do estabelecimento de condiçóes e possibilidades favoráveis ao incremento e reprodução do saber sociologico. Exatamente por isso, os professores da misstio francesn desempenharam um papel essencial, ainda que nâo exclusivo, ao exercício da disciplina no Brasil. Se os franceses foram os grandes mestres, norte-americanos e alemães, alojados na Escola Livre de Sociologia e Política, concorreram para a abertura de temas de investigação que, posteriormente, se configuraram 
em estudos desenvolvidos na USP. Nessa área específica, encontram-se as pesquisas de Donald Pierson sobre Negros in Brazil: a study of. race contact at Babia, sua tese de doutoramento, escrita em 1942, o clássico trabalho sobre Cruz das Almas, iniciado em 1947 que, juntamente com a pesquisa de Emílio Willems sobre Cunha, publicada em 1946, transformaram-se em paradigma para os estudos sobre comunidade, uma das vertentes importantes das Ciências Sociais em São Paulo. Concomitantemente, outro professor da Escola Livre de Sociologia e Política, Herbert Baldus, alemão como Willems, contribuiu para a formação de futuros pesquisadores da Universidade de São Paulo. Em suma, a sociologia praticada na USP náo resultou, exclusivamente, do transplante de um departamento francés de ultramar, apesar da presença indelével dos professores franceses entre nós.

Os mestres franceses proporcionaram-nos, suplementarmente, a vivência de uma ambiência universitária, a formação acadêmica, enfim, o estilo de pensamento próprio à instituição. Foram os principais responsáveis, por isso, na conformação do perfil institucional, no qual sobrelevaram as personalidades de Paul Arbousse-Bastide e principalmente Roger Bastide. Nessa tarefa, outra figura central adquire relevo: Fernando de Azevedo, um dos mentores da reforma educacional na sua face progressista, redator dos Estatutos da Universidade, professor catedrático de Sociologia Educacional e diretor da Faculdade de Filosofia. Homem devotado à tarefa de consolidar a Faculdade e as Ciências Sociais em São Paulo, Fernando de Azevedo conservou a qualidade de construtor institucional, o que era visível na escolha dos seus colaboradores.

Dentre os franceses, destaca-se a participação notável de Roger Bastide ao dirigir suas preocupaçōes para temas brasileiros. Estudioso de múltiplos interesses, refletiu sobre assuntos variados: de Les problemes de la vie mystique (1931), passando por Psicanálise do cafuné e Ensaios de sociologia estética brasileira (1941), à Poesia afro-brasileira (1943); no conjunto dos seus trabalhos, os estudos sobre relaçóes raciais e religiōes afro-brasileiras são portadores de tendências de investigação desenvolvidas posteriormente; a pesquisa sobre as Relaföes entre negros e brancos em São Paulo, realizada em conjunto com Florestan Fernandes, e publicada em 1955, abre o interesse pelo tema na sociologia da USP, além de moldar uma determinada forma de tratamento. O mesmo ocorreu com os seus livros $O$ candomblé na Babia: rito nago (1958) e As Religiōes Africanas no Brasil (1960), clássicos da análise sociológica sobre as expressóes brasileiras da religiosidade popular. A obra de Roger Bastide dedicada ao Brasil manifesta, incontestavelmente, a qualidade de erigir temas e conformar uma modalidade de reflexão, presente de forma atua- 


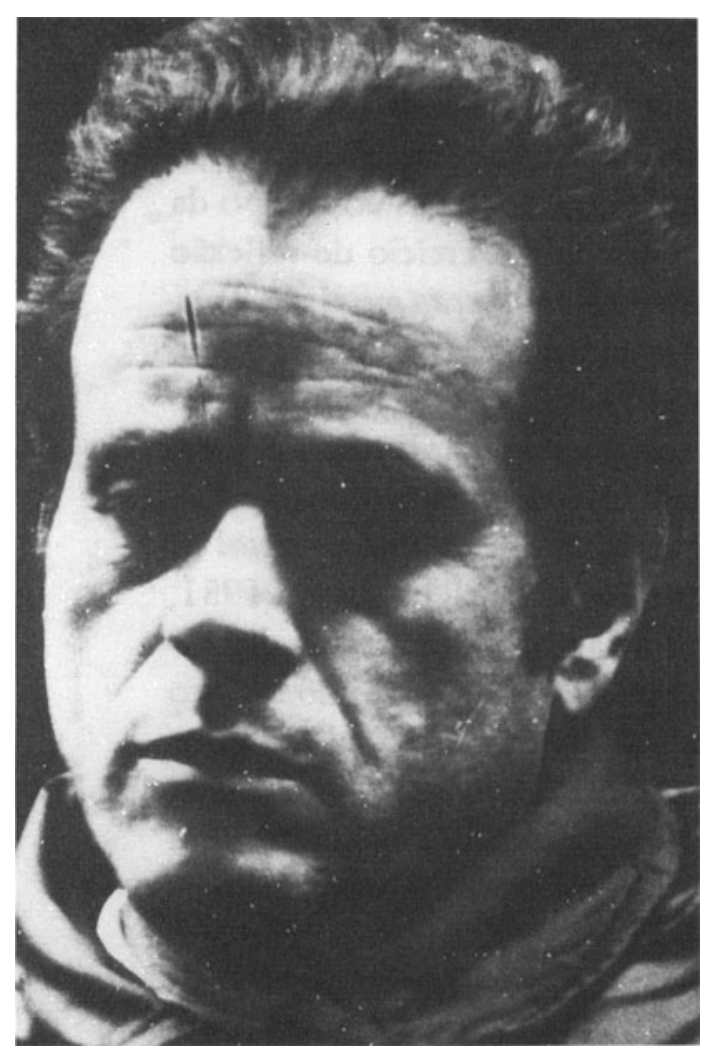

Duglas Teixeira Monteiro

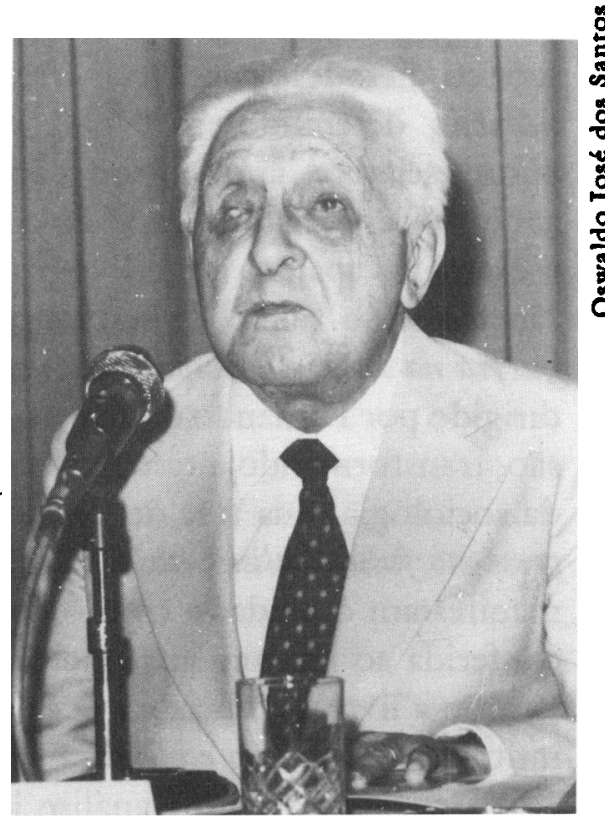

Aziz Simão

lizada e mesmo transformada nos trabalhos da primeira geração de sociólogos formados pela USP.

A partir desse momento, a consolidaçáo da sociologia acadêmica em Sáo Paulo só se realiza, plenamente, através da elaboraçáo dos primeiros trabalhos dos sociólogos criados na Universidade. Nessas obras, visualiza-se a presença das referências recebidas, o seu aproveitamento, as superaçóes $\mathrm{e} O$ assentamento das balizas futuras da investigação. $\mathrm{Em}$ outros termos, é da confluência entre as orientaçóes recebidas e a possibilidade de constituir uma experiência em pesquisa, que resulta a implantaçáo da sociologia acadêmica. Nesse primeiro momento, a sua expressáo mais candente localiza-se na associaçáo entre o exercício de reflexáo teórico-metodológica, combinada ao recorte original de objetos de conhecimento. $O$ exame das teorias e dos procedimentos adequados constituir-se-á num emblema da sociologia universitária paulista, na fase do seu estabelecimento.

$* * *$

Os primeiros trabalhos produzidos pelos sociológos, formados pela USP, revelam a presença de uma abertura em leque das preocupaçóes temáticas, indicando a tentativa de construir objetos próprios de 
investigaçáo e de assentar as formas de tratamento. Nesse sentido, sáo ilustrativas as teses de mestrado e doutorado de Florestan Fernandes, a respeito dos índios Tupinambás. Aparentemente adstritas ao campo da etnologia, essas obras são bastante marcadas pelo exercício de reflexão teórico-metodológica. No mestrado, com a Organizafáo social dos Tupinambás, defendido em 1948 e sob a orientaçăo de Herbert Baldus, o autor esclarece, já na introdução, que a sua concepção sobre a organizaçáo social é distinta da visáo corrente dos sociológos. Dessa maneira, o exame do aparato metodológico ordena o trabalho, fazendo da discussão teórica o fulcro de seu empreendimento. Com $A$ funf̧ũo social da guerra na sociedade Tupinambá, seu doutoramento, defendido em 1951, dirigido por Fernando de Azevedo, Florestan amplia o escopo da discussão, transformando a tese num exercício de erudição teórica, no âmbito da sociologia. Sua tese de livre-docência Ensaio sobre o método de interpretafão funcionalista na sociologia, de 1953 e vários outros escritos, manifestam o cuidado com o conhecimento da teoria e a importância conferida ao instrumental metodológico. As mesmas inquietaçóes perpassam a livre-docência e a tese de cátedra de Ruy Coelho. A primeira, intitulada Indipiduo e sociedade na teoria de Auguisto Comte, escrita em 1961, tratando de uma análise interna dessas noções, elaboradas pelo fundador da sociologia, na qual são ressaltadas as suas implicaçóes conceituais. A segunda, Estrutura social e personalidade, de 1964, visa a discutir as linbas mais relepantes do conceito de estrutura. Os temas ligados à teoria sociológica caracterizam, em grande medida, as orientaçōes da primeira geração de sociológos.

Nesse quadro, a tese de Gilda de Mello e Souza $A$ moda no século $X I X$ (1950), recorta um tema ímpar no cenário da sociologia de então. Com esse trabalho, a autora, além de introduzir um tema original, demonstra a forte presença de Roger Bastide na sua formação, dado que os problemas da arte e da estética ocuparam parte das preocupaçóes do professor francês. O mesmo pode ser dito do doutoramento de Antônio Cândido - Os Parceiros do rio Bonito: estudo sobre os meios de subsistencia do caipira paulista, defendido em 1954, centrado na análise das manifestaçóes e mudanças da cultura caipira. Essa obra, contudo, assenta cértas questóes que vão pontuar a reflexão sociológica, pelo menos até o fim dos anos 60 e início dos 70: os problemas provocados pela crise de transição de uma sociedade em processo de mudança. $O$ universo rural, segundo a análise de Antônio Cândido, encontra-se em desagregação, está perpassado pela crise. Esse texto, suplementarmente, espelha o estado de construção da sociologia universitária em São Paulo na época, onde os domínios disciplinares estão interligados, isto $\dot{\epsilon}$, as fronteiras específicas não aparecem demarcadas. $O$ trânsito entre as abordagens da 
sociologia, antropologia e política é corrente. Se no estudo de Antônio Cândido, a análise de grupos primitivos e homogêneos é tipicamente antropológica, é por outro lado sociológica a investigação das sociedades civilizadas, num vasto território e com grande populaçáo. A mesma confluência é perceptível nos estudos de Florestan Fernandes sobre as sociedades indígenas e nos trabalhos de Maria Isaura Pereira de Queiroz sobre o messianismo. As duas teses da socióloga, La guerre sainte ane Brésil: le mouvement messianique du contestado e Movimentos messidnicos: tentatipa de classificafáo sociologica escritas, respectivamente, em 1954 e 1964, apesar de a perspectiva analítica ancorar-se no campo da sociologia, tratam de objetos afeitos a contextos tradicionais e mesmo primitivos. É de notar-se a participação efetiva do seu mestre Roger Bastide na escolha de um tema na área da religião. Maria Isaura desempenhou, concomitantemente, papel relevante no âmbito institucional, quando formou, em 1964, o CERU - Centro de Estudos Rurais e Urbanos - que mantém, até hoje, intensa atividade de pesquisa. Na mesma linha temática desenvolvida pela professora, encontram-se as pesquisas de Duglas Teixeira Monteiro sobre o milenarismo. Os errantes do nopo século: um estudo sobre o surto milenarista do contestado, foi sua tese de doutoramento.

Uma outra vertente de investigaçáo abre-se, no decorrer da década de 50: são os estudos sobre relaçóes raciais, iniciados na USP, a partir do projeto de Roger Bastide e Florestan Fernandes. A tendência fundamental da análise reside na inserçáo do preconceito e das relaçóes desencadeadas pelo fenômeno na estrutura social. Os autores orientam as suas reflexóes, no interior da consideração de situaçóes sociais propícias à emergência do preconceito. Em torno do tema do negro, Florestan Fernandes dirige pesquisas importantes, voltadas ao estudo das relaçóes raciais, na gênese e desenvolvimento da sociedade brasileira. Encontram-se nesse campo de preocupaçóes, o doutoramento de Fernándo Henrique Cardoso - Formagaio e desintegraficio da sociedade de castas: 0 negro na ordem escravocrata do Rio Grande do Sul defendido em 1961; de Octávio Ianni $O$ negro na sociedade de castas do mesmo ano; a tese de Maria Sylvia de Carvalho Franco Homens lipres na velha civilizafáo do cafte (1964); e a tese de Juarez Rubens Brandão Lopes - Crises do Brasil arcaico - que se aproxima, em termos de preocupaçóes, das anteriores.

Há novas características, no entanto, que marcam a produçáo dessa segunda geração de sociólogos da USP, mesmo à luz da presença de certas persistências. Em primeiro lugar, a ênfase na estrutura social faz perder força recortes e tratamentos transdisciplinares; em segundo, o exercício teórico, se náo desapareceu, centrou-se no exame privilegiado de uma das contribuições clássicas, qual seja o marxismo, como 
produto do conhecido Seminário de Marx que congregou professores das Ciências Sociais, Filosofia, História e Economia. O resultado desse seminário foi a realizaçáo de trabalhos marcantes nessas diversas disciplinas e, no que tange à sociologia, o doutoramento de Fernando Henrique Cardoso é paradigmático; terceiro, porque emergem temas voltados ao conhecimento da sociedade industrial no Brasil, os atores sociais envolvidos no processo, impasses da modernização, políticas de desenvolvimento, enfim, um conjunto amplo de enfoques dirigidos à compreensão dos fenômenos urbanos. Nesse novo campo de estudos, aliás, os trabalhos de Azis Simão, pertencente à primeira geraçáo, sấo em certa medida precursores. O poto operário em Sáo Paulo e Sindicato e Estado obras hoje clássicas do gênero e que, apesar de escritas, em 1964, demonstram a sensibilidade do sociólogo para o conhecimento das questóes pertinentes à nova realidade brasileira. Ainda na categoria de trabalho precursor, está a tese de Lucilla Hermann - Flutuafăo e mobilidade da mão-de-obra fabril em São Paulo, de 1948.

A inquietaçáo em torno da mudança social e dos princípios de estruturação da sociedade de classes tem, aliás, forte registro na segunda geração. São exemplares, dessa tendência, os doutoramentos de Luís Pereira - O magistério primário na sociedade de classes (1961) e de Marialice Forachi - Estudante e transformafão na sociedade brasileira defendido em 1964. Em ambos, a persistência com a questão educacional, já presente no mestrado, aparece inserida no novo quadro de orientaçōes. Ainda no campo da sociologia educacional outros trabalhos foram realizados.

A compreensáo da dinâmica das pesquisas, desenvolvidas na sociologia da USP, não se elucida sem a consideração do núcleo congregado no Cesit - Centro de Sociologia Industrial e do Trabalho constituído em 1962 por Fernando Henrique Cardoso e Florestan Fernandes e que reuniu recém-formados, sob a orientaçáo dos professores da Cadeira de Sociologia I. O centro permitiu a realizaçáo de trabalhos dedicados ao novo campo de estudos. A livre-docência de Fernando Henrique Cardoso Empresário industrial e desenvolvimento econdmico (1963), as teses de Leôncio Martins Rodrigues Manifestạcóes e funfóes do conflito industrial em São Paulo e Atitudes operdirias na empresa automobilistica: estudo de um grupo de trabalhadores e a de Octávio Ianni - $O$ Estado e o desenvolpimento econdmico no Brasil sáo produtos das pesquisas desenvolvidas no Cesit. Com essas obras, os sociólogos da USP sintonizam os problemas emergentes do Brasil na época, a partir do estilo acadêmico de reflexão.

O elenco desses trabalhos atesta a presença vigorosa da sociologia 
da USP, no interior da Faculdade de Filosofia, além do caráter institucionalizado da disciplina nos quadros da universidade e mesmo fora dos seus limites. A tese de cátedra de Fernando Henrique Cardoso - Politica e desenvolvimento em sociedades dependentes: ideologia do empresariado industrial argentino e brasileiro - cristaliza a formulaçáo da chamada teoria da dependencia, afirmando a densidade adquirida pelos estudos sociológicos na Universidade de São Paulo.

O exemplo mais marcante da constituição da sociologia acadêmica encontra-se, no entanto, expresso na vasta obra de Florestan Fernandes. Personalidade intelectual multifacetada, o sociólogo combinou uma produçáo que se dirigia, ao mesmo tempo, para a discussão teóricometodológica, com vistas a atingir um quadro conceitual seguro e capaz de informar análises rigorosas, ao trabalho de investigaçáo voltado para o conhecimento da sociedade brasileira. Florestan foi um homem perseguido pela tarefa de construir a ciência sociológica no Brasil, enquanto foi professor da Universidade de São Paulo. Por isso, atuou, simultaneamente, em dois pólos: mapeava temas e erigia um estilo de reflexáo pautado por princípios da produção do conhecimento. A magnitude do seu empreendimento pode ser vislumbrada no caráter eclético das suas discussōes teórico-metodológicas, tendo em vista sorver diferentes contribuiçóes, para fundamentar o que ele denominava de "conhecimento ativo e integrado na própria situação estudada". Daí, a dimensáo forte de sua obra e a originalidade das suas reflexóes sobre a sociedade brasileira. O seu livro - $A$ integração do negro na sociedade de classes originalmente sua tese de cátedra, defendida em 1964, elucida o tratamento peculiar oferecido ao tema e certas concepçóes que acaba construindo sobre o Brasil. Na obra, a problemática do negro é revisitada à luz das noçóes de classe e de mudança do padrão societário, mostrando a exclusão social vivenciada pelos ex-escravos. Nesses termos, a análise aponta para padróes diferenciais, ou, mais especificamente, para a presença de uma modernidade travada, dado à persistência do arcaico no novo. Em $A$ revolugão burguesa no Brasil amplia-se o universo dessa problemática, conferindo ao texto a densidade das grandes interpretações do país. Através de uma análise pontuada por referências sociológicas nítidas, onde as principais contribuiçóes são absorvidas de modo singular, o professor constrói uma visão particular do Brasil. Paralelamente à urdidura da sua obra, Florestan formou um grupo de sociólogos que trabalhavam articuladamente. Atuou no campo do reconhecimento da profissáo, da institucionalização da pesquisa e desenvolveu açóes de natureza claramente intervencionista, como no caso da campanha em defesa da escola pública. Mas, sobretudo, consolidou um modo de produzir conhecimento em sociologia e assentou a necessidade da 
transmissáo de procedimentos indispensáveis à realização das pesquisas. A hegemonia intelectual da cadeira de Sociologia I, dirigida por Florestan, referenda a importância adquirida pelo grupo que congregou e que passou a ser identificada pela expressáo escola paulista de sociologia. A trajetória e a obra de Florestan Fernandes permitem que se lhe atribua o papel de artífice fundamental, na história da construçáo da sociologia acadêmica no Brasil.

$$
\text { *** }
$$

A continuidade desse processo intelectual e acadêmico ficou comprometida, pelos efeitos que o AI-5 provocou na vida universitária e intelectual brasileira. $\mathrm{O}$ afastamento arbitrário de Florestan Fernandes, Fernando Henrique Cardoso e Octávio Ianni implicou a perda de certas direções da pesquisa e, além do mais, amordaçou o desenvolvimento das reflexóes que exigem, para vicejar, liberdade irrestrita de pensamento. A reforma universitária também alterou o perfil institucional que a Faculdade de Filosofia havia construído, em mais de trinta anos. $O$ período que se abre foi, então, caracterizado pelo esforço em retomar orientaçóes assentadas e em manter a integridade do exercício de ensino e pesquisa, violentamente atingida. A tarefa de reconstrução coube aos antigos e novos professores que permaneceram, cujo esforço desmedido permitiu preservar e reordenar os princípios da formação. $O$ desenho da pesquisa no Departamento de Sociologia é, em larga medida, tributário do denodo dos mestres que ficaram, cuja missão foi a de atuar, simultaneamente, em duas frentes: a da reorganizaçáo institucional e a da manutençáo de vivo interesse pela pesquisa.

O formato atual resultou da combinação entre a tradiçáo recebida, acoplada à abertura de novos objetos de investigaçáo, produzidos na esteira das transformaçóes da sociedade brasileira, pelo menos nos últimos vinte anos. As sete grandes áreas abrigam múltiplas linhas de pesquisa, expressando diversos interesses, demonstrando, no entanto, coerência de diretrizes na formação de novos sociólogos.

- Teoria Sociológica, Metodologia e Epistemologia. Essa área congrega estudos voltados tanto ao reexame da tradiçăo clássica, quanto à consideração das vertentes principais do pensamento contemporâneo. Agasalha as análises interdisciplinares que foram reforçadas nos últimos anos, frente à chamada crise dos paradigmas das ciências sociais: sociologia e psicanálise; fundamentos filosóficos da teoria sociológica; sociologia e história (o problema da temporalidade e da reconstruçăo histórica); teorias da identidade e do sujeito no âmbito das ciências humanas; trabalhos de epistemologia e metodologia, especialmente, metodologia analítica. 
- Sociologia da Cultura e da Educafão. Reúne pesquisas variadas sobre instituiçōes, expressões culturais, história intelectual e processos intelectuais contemporâneos. No âmbito dessa área, são desenvolvidas investigaçóes sobre história social da arte: instituiçōes culturais (universidade, museus, outros órgáos culturais); pensamento social brasileiro; formação e institucionalização das ciências sociais no Brasil; sociologia da comunicaçăo de massas; sociologia dos processos culturais de consumo; construçáo simbólica e imaginário social nas sociedades contemporâneas; fundamentos e processos educacionais.

- Sociologia dos Processos Politicos e das Instituigóes Puíblicas. Dirige-se para consideraçáo de processos políticos e das instituiçōes correlatas. No interior dessa área, são realizadas pesquisas sobre regimes; partidos e formas de representação; processos eleitorais; cidadania e participação política; instituiçóes jurídicas; exercício da violência social e política; políticas públicas (previdência social e saúde); relaçóes internacionais (Mercosul, Comunidade Européia e África).

- Sociedade Capitalista e Classes Sociais no Brasil. Abriga trabalhos sobre a particularidade da formação das classes sociais no Brasil, a constituiçáo das relaçóes capitalistas, estudos sobre a dinâmica urbana e agrária e atores sociais envolvidos na história do capitalismo brasileiro. Nessé sentido, a área desenvolve investigaçóes sobre processos de trabalho, movimento de trabalhadores, acidentes e violência no trabalho, órgáos patronaiś e sindicatos de trabalhadores, empresariado, campesinato, questão agrária, imigração e problemas da metrópole moderna.

- Sociologia da Religião. Área de interesse tradicional na sociologia da USP, as pesquisas têm revelado a abertura de novas sendas de investigaçáo. A análise das instituiçóes religiosas e da religiosidade popular expressam o andamento das pesquisas aí envolvidas: Igreja Católica, Protestantismo, Pentecostalismo, Candomblé, Umbanda, Espiritismo têm sido analisados sobre o crivo da dinâmica cultural contemporânea, de processos políticos e das formas de representaçáo política dos fiéis e adeptos de princípios religiosos.

- Relaçóes Sociais de Género. As linhas de pesquisa dessa área centram-se no conhecimento da história e da participaçáo da mulher na sociedade brasileira, nos seus vários campos de atuação: no trabalho, na política, nas associações femininas e culturais, enfim, trazem para a cena a problemática da constituiçáo dos direitos da mulher na sociedade brasileira.

- Estudos sobre a América Latina e Africa Negra. Nessa área multipli- 
cam-se linhas de pesquisas voltadas para o conhecimento das realidades latino-americana $\mathrm{e}$ africana. No que tange à América Latina, os trabalhos enfocam, prioritariamente, a questáo da identidade do continente, transformaçóes econômicas, políticas e culturais das últimas décadas, impasses e problemas do desenvolvimento. Os estudos sobre a África Negra estão congregados no Centro de Estudos Africanos, ligado ao Departamento de Sociologia, no qual são desenvolvidas investigaçóes diversas sobre a dinâmica das transformaçôes econômicas, sociais e políticas, as particularidades culturais, inclusive lingüísticas e étnicas.

Esta síntese da trajetória da pesquisa na sociologia da USP, apesar do seu caráter incompleto, permite vislumbrar os caminhos trilhados, da origem aos dias de hoje. O perfil atual da pesquisa, a multiplicidade das linhas de interesse, deriva do contingenciamento inelutável do movimento da história. Se essa história não transcorreu de modo harmonioso, dilaceramentos e rupturas a marcaram, o resultado final preservou o sentido fundamental da formação, estabelecido na gênese da Faculdade de Filosofia da USP.

Maria Aminda do Nascimento Amuda é professora do Departamento de Sociologia da Faculdade de Filosofia, Letras e Ciências Humanas da USP. 